ESKIŞEHİR TECHNICAL UNIVERSITY JOURNAL OF SCIENCE AND TECHNOLOGY A- APPLIED SCIENCES AND ENGINEERING

$2021,22(2)$, pp. 175-188, DOI: 10.18038 /estubtda. 896491

RESEARCH ARTICLE

\title{
CORRELATION BETWEEN SPT AND PMT RESULTS FOR SANDY AND CLAYEY SOILS
}

\author{
Özgür YILDIZ * \\ Department of Civil Engineering, Faculty of Engineering and Natural Sciences, \\ Malatya Turgut Özal University, Malatya, Turkey
}

\begin{abstract}
Determination of soil deformation and strength properties is of great importance in geotechnical design. The disturbance that occurred during the sampling from the field affects the results obtained by the laboratory tests. Therefore, the lack of representation of the field conditions and in-situ soil features with laboratory tests leads the designers to carry out field tests. Standard penetration test (SPT) and the Menard pressuremeter test (PMT) are the most widely used geotechnical field tests in which the results are utilized to investigate soil properties and lateral deformation characteristics at a specified depth. In this study, a total of 102 data of sandy and clayey soils belonging to the geotechnical investigations carried out in Istanbul were compiled. The regression analysis between the corrected SPT blow count N60, pressuremeter modulus EpMT, limit pressure PL and $\mathrm{E}_{\mathrm{PMT}} / \mathrm{P}_{\mathrm{L}}$ ratio is performed. Empirical equations were separately developed for sandy and clayey soils between the considered parameters. The developed equations showed that there are acceptable relationships between the parameters examined in the particular dataset. Moreover, a neural network (NN) based prediction model was developed to predict EPMT and $P_{L}$ using the available soil data. The highly accurate prediction performance of the proposed model demonstrated the availability of modern methods for the estimation of soil parameters.
\end{abstract}

Keywords: Standard penetration test, Pressuremeter test, Correlation, Prediction model, Neural network

\section{INTRODUCTION}

Field investigation studies and determination of the soil properties are of great importance for geotechnical design. Successfully determined soil parameters contribute to the performance of the civil engineering structures. The tests in geotechnical soil investigation studies are divided into two categories namely; i. field tests, ii. laboratory tests. These studies are based on sampling from the field and/or determining the soil properties without sampling but through in-situ tests. The main objective of these studies in both of the categories is to obtain the soil parameters that will accurately represent the in-situ soil properties. However, the difficulties in undisturbed sampling make test results questionable. Although the sample obtained from the drilling is assumed to be undisturbed, factors such as the drilling and motion, water and air pressure applied, number of drilling cycles, separating the sample from its origin, contact of atmospheric conditions, time until the test, etc. make it impossible. Therefore, the importance of field tests increases since the laboratory tests sometimes do not adequately represent the in-situ soil properties.

The SPT and PMT are the most widely used field tests to define soil type, stratigraphy, and deformation parameters, and calculate foundation bearing capacity and subsidence settlement. The standard penetration test is used by dropping a $63.6 \mathrm{~kg}$ ram from a height of $76 \mathrm{~cm}$ and pushing the rod into the soil [1]. The test consists of driving the standard split sampler a distance of $46 \mathrm{~cm}$ to the soil and counting the ram drop required to push the sampler to the ground for the last two $15 \mathrm{~cm}$. The boring log shows refusal if 50 blows are required for any $15 \mathrm{~cm}$ distance, 100 blows are obtained for a $30 \mathrm{~cm}$ distance or 10 drops produce no advance. It is popularized by Terzaghi and Peck [2] as a type of test which is useful to estimate the engineering properties of soils. To interpret the results of SPT correctly, the equipment,

* Corresponding Author: ozguryildiz56@gmail.com

Received: 14.03.2021 Published: 29.06.2021 
the mechanism of the experiment, and the method should be known correctly. Many parameters affect the result of the test. Penetration resistance may differ depending on these variables, which will affect the validity and usability of the test results.

A set of corrections for; groundwater, rod energy ratio, rod length, sample barrel, and borehole diameter are applied to raw blow counts, thus, the corrected blow count, $\mathrm{N}_{60}$ is obtained. Since the SPT-N number is a measure of strength properties of soil, the structures built with reference to unrealistically high SPT$\mathrm{N}$ numbers may encounter foundation problems or settlements. On the contrary, the design of the structure is based on a very low SPT-N number than it is, maybe considered as over-design.

The pressuremeter is an in-situ test in which the stress-strain response of the soil is determined. The experiment is carried out simply by inflating an expandable cylindrical probe in a pre-drilled well and measuring the pressure and the volume changes in the probe. It is a test method applied especially in sandy, clayey, silty, alluvial soil and rock formations to calculate the bearing capacity of the soil and the settlement under the foundation. Although this testing mechanism was first proposed by Kögler [3] in order to determine the deformation properties of soils, the device was developed by Menard [4] and is known as the pressuremeter with the same name. The 'Menard Pressuremeter' device consists of the read-out unit and the probe which is inserted into the drilled borehole. When the part of the equipment called the probe is lowered to the desired soil depth along the drilled hole, the guard cell is inflated and the measuring cell applied pressure to the borehole wall. After the pressure causing deformation in the borehole wall is kept constant for a while, the volumetric increase required for the constant pressure level is noted. A typical curve of PMT is shown in Figure 1. Approximate values of the pressuremeter for sands and clays are presented in Table 1.

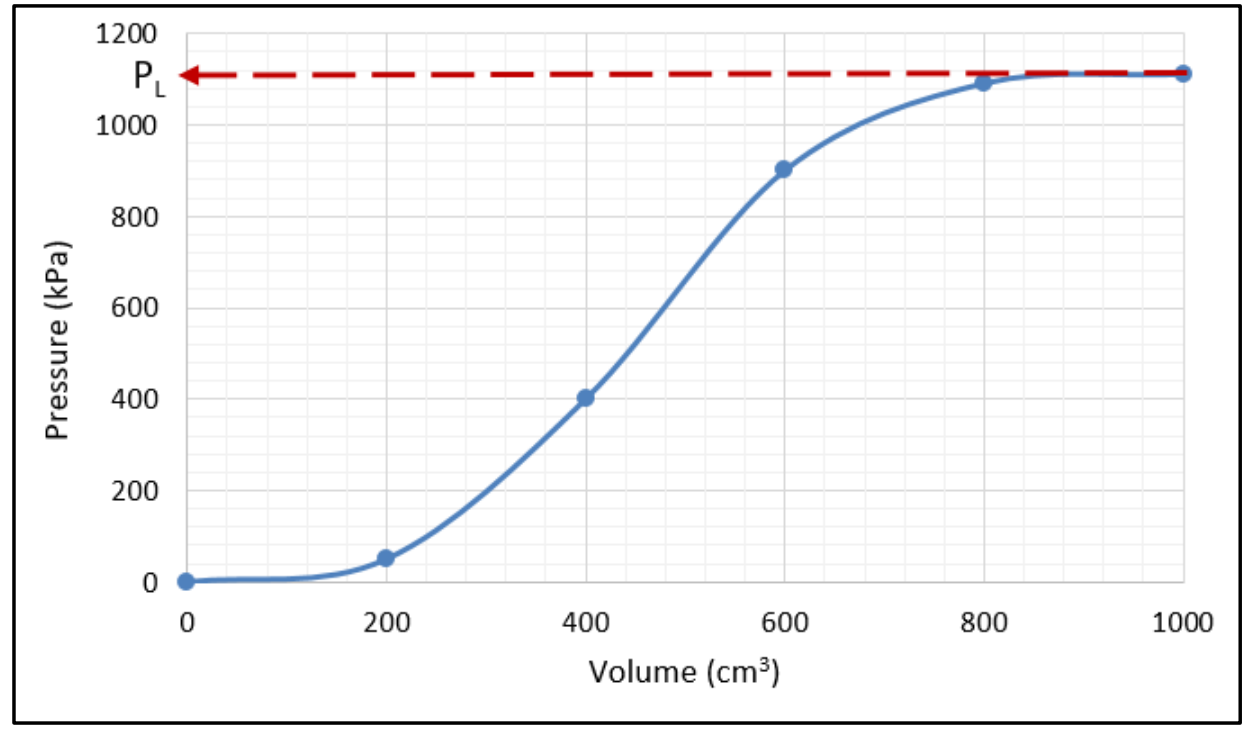

Figure 1. A typical pressuremeter testing curve

Table 1. Approximate values of pressuremeter for sand and clays

\begin{tabular}{ccccccccc}
\hline Parameter & \multicolumn{4}{c}{ Sand } & \multicolumn{3}{c}{ Clay } \\
\cline { 2 - 9 } & Loose & Medium & Dense & Very dense & Soft & Medium & Stiff & Very stiff \\
\hline $\mathbf{P}_{\mathbf{m}}(\mathbf{M P a})$ & $0-0.5$ & $0.5-1.5$ & $1.5-2.5$ & $>2.5$ & $0-0.2$ & $0.2-0.4$ & $0.4-0.8$ & $0.8-1.6$ \\
\hline EPMT $($ MPa) & $0-3.5$ & $3.5-12$ & $12-22.5$ & $>22.5$ & $0-2.5$ & $2.5-5$ & $5-12$ & $12-25$ \\
\hline
\end{tabular}


As stated above, the mechanism and duration of testing for both methods are different from each other. In pressiometer tests, a reasonable time is allowed for the soil deformation while applying pressure to the borehole walls. On the other hand, the SPT test is an experiment that takes place instantly by dropping the ram into the soil. In the pressuremeter test, the deformation characteristics of the soil under lateral pressure, and in the SPT test, the vertical resistance of the soil against dropping ram is measured. In both test types, the applied direction of pressure is different from each other. This brings to mind an anisotropy due to the different directions of application. Researchers stated that the horizontal and vertical stiffness obtained from in-situ tests are similar $[5,6,7]$. Therefore, it is thought that this issue can be eliminated if the tests were applied at the same depths.

The correlations between the field and laboratory test results have been examined by many researchers. These correlations are usually made through regression analysis if the auxiliary data association methods are not used. Regression analysis is a method used to measure the relationship between two or more variables. With this analysis, knowledge can be obtained about the relationship between variables and their level. In this context, the correlation studies conducted between field tests, especially SPT and PMT results are diverse. Ohya et al. [8] developed correlations between SPT-N value and EPMT for clay soils. Briaud [9] proposed correlations between PMT and SPT results using the data of a total of 80 soil formations, 36 of which are sand, 44 of which are the clay. Gonin et al. [10] developed correlations for different types of soil. Yagiz et al. [11] performed studies on the relationship between corrected SPT-N values, $E_{P M T}$ and $P_{L}$ throughout a case study conducted in Denizli. The authors obtained sufficiently higher correlation coefficients between SPT-N-E $E_{P M T}$ and SPT-N-P , as 0.907 and 0.966 , respectively. Alzubaidi [12] utilized three different methods namely; i. Menard, ii. Gibson and Anderson iii. Palmer methods to interpret $\mathrm{E}_{\mathrm{PMT}}$ value. Kenmogne and Martin [13] obtained a linear correlation between SPT$\mathrm{N}, \mathrm{P}_{\mathrm{L}}$ and $\mathrm{E}_{\mathrm{PMT}}$ for clean sand, gravely sand, sandy clay and gravely clays. Cheshomi and Ghodrati [14] developed correlations between SPT- $\mathrm{N}_{60}-\mathrm{E}_{\mathrm{PMT}}, \mathrm{N}_{60}-\mathrm{P}_{\mathrm{L}}$ and $\mathrm{E}_{\mathrm{PMT}}-\mathrm{P}_{\mathrm{L}}$ for silty sand and silty clays using 54 sets of test data. Anwar [15] developed relationships between SPT-N - EPMT for three soil groups having different grain size distribution and carbonate content. Bozbey and Togrol [16] proposed correlations for sandy and clayey soils using 182 sets of data belonging to the geotechnical investigations from Istanbul. Kayabasi [17] studied soil data obtained from a geotechnical investigation of a sewerage station foundation in Mersin in which the investigation area mainly consists of clayey soils. A set of empirical equations developed by the author between pressuremeter modulus, $\mathrm{E}_{\mathrm{PMT}}$ and corrected SPT blow counts, $\mathrm{N}_{60}$ and between limit pressure, $\mathrm{P}_{\mathrm{L}}$ and corrected SPT blow counts, $\mathrm{N}_{60}$. Aladag et al. [18] developed a neural network model to predict $\mathrm{E}_{\mathrm{PMT}}$ and $\mathrm{P}_{\mathrm{L}}$ of clayey soils. Agan [19] investigated the relationship between PMT, SPT and laboratory test data for silty sands of a region, Kastamonu, Turkey.

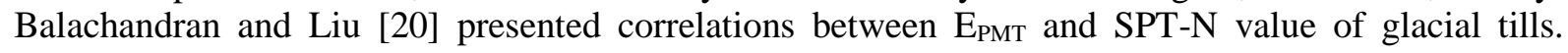
Narimani et al. [21] developed simple and nonlinear regression models to correlate SPT, compression and pressuremeter test data. Kavur et al. [22] established correlations between cone penetration, pressuremeter and standard penetration test results for a testing location consisting of gravelly and clayey soil layers. Ceylan and Önal [23] proposed correlations for alluvial deposits from a local region in the Battalgazi district of Malatya, Turkey. Zaki et al. [24] predicted the pressuremeter modulus using the group method of data handling (GMDH) neural networks. There are also different studies conducted by researchers to develop correlations for particular regions between parameters obtained by field and laboratory tests. It is stated that local correlations developed for a particular geological environment will generally give more accurate results than global correlations [25].

In this study, a total of 102 soil test data, 47 of which are belonging to sandy and 55 of which are belonging to clayey formations, compiled from the field investigations in Istanbul. Linear regression analysis was performed between the corrected SPT blow count $\mathrm{N}_{60}$, pressuremeter modulus $\mathrm{E}_{\mathrm{PMT}}$, limit pressure $\mathrm{P}_{\mathrm{L}}$ and $\mathrm{E}_{\mathrm{PMT}} / \mathrm{P}_{\mathrm{L}}$ ratio. A NN-based prediction model has been developed to estimate $\mathrm{E}_{\mathrm{PMT}}$ and $\mathrm{P}_{\mathrm{L}}$ using the available data. The performance of the developed prediction model has been examined through $\mathrm{R}^{2}$ correlation coefficients. The availability of modern data processing methods is demonstrated as a preliminary design stage study for civil engineering projects. 


\section{METHODOLOGY}

In this study, 102 soil data belonging to a total of 30 borehole logs from Istanbul were examined. The geological structure of the region consists of formations with lithologies that can frequently change from bottom to top with the erosion of the region. Arkoz and quartzites have a very hard rock appearance and sometimes completely sand content. The greywackes are known as the Trakya formation consisting of limestone sandstone, siltstone and claystone alteration which has been affected by intense tectonic events and faults, fractures and joints in different directions every few meters. The Kirklareli formation consisting of limestone, marl and carbonate claystone, with an approximate thickness of $150 \mathrm{~m}$, of Eocene age, medium, thick-bedded, karst voids, abundant fossils, rests on this formation. Above, Gürpınar formation which is more than 700 meters thick, Oligocene aged, hard clay-claystone with tight sand-sandstone lenses exist. Above the Gürpınar Formation, there are Miocene-aged sedimentary units. The first unit of the Miocene age is the Çukurçeşme Formation. This formation consists of approximately $25 \mathrm{~m}$ thick unattached sand layers with lenses of clay in between. On top of this unit, the Güngören Formation consists of greenish-gray, light brown colored clay layers with fine sand lenses. The uppermost unit distinguished in the Miocene sequence is the Bakırköy Formation of $20 \mathrm{~m}$ thickness mainly formed by marl and limestone. There are alluvial deposits on these units which are mainly composed of yellow-brown colored sand and silty clays. The Golden Horn sediments, on the other hand, consist of silty clay deposits with a thickness of about 35 meters, deposited in a stagnant environment. On these deposits, the ancient and the current filling materials reach up to 30 meters. Yildirim et al. [26] stated that the Gürpınar, Çukurçeşme and Güngören Formations are actually a single alternative series of clay-sand/sandstone deposits/lenses. All three units are collectively named as 'Avc1lar Formation' due to the difficulties experienced in identifying the soil formations encountered during field studies.

The analyzed soil data belong to sandy and clayey units at different depths of the Avc1lar formation. The depths of borings are ranged between 4 to $59.55 \mathrm{~m}$. The groundwater level is ranged between 10.5 to $55.2 \mathrm{~m}$. The standard penetration and pressuremeter tests are performed at the same depth. Data of 102 specimens, 47 of which were sandy and 55 were clayey, were analyzed. Since the accuracy of the selected data has an influence on the reliability of analysis results, the most representative parameters used and some were eliminated. Equations created through graphs and regression curves obtained by statistical analysis. The correlation between the selected variable pairs was evaluated with reference to the regression curves and $\mathrm{R}^{2}$ values.

\section{RESULTS and DISCUSSION}

The histogram of the compiled test data namely; $\mathrm{E}_{\mathrm{PMT}}, \mathrm{P}_{\mathrm{L}}$ and SPT-N $\mathrm{N}_{60}$ are given in Figure 2. The variation of the SPT-N $\mathrm{N}_{60}$ values with depth for sandy and clayey soils is collectively presented in Figure $3 \mathrm{a}$. As can be seen from the graph, the increase in soil depth leads to an increase in SPT-N60. The SPT$\mathrm{N}_{60}$ blows ranged between 6 to 67 with an average of 44 and a standard deviation of $19.4 \mathrm{MPa}$. Figure $3 \mathrm{~b}$ shows the variation of pressuremeter modulus, $\mathrm{E}_{\mathrm{PMT}}$, with depth. Measured $\mathrm{E}_{\mathrm{PMT}}$ values ranged between 6 and $44 \mathrm{MPa}$, with an average of $21.7 \mathrm{MPa}$ and a standard deviation of 9.5 MPa. It is observed to increase with increasing depth. Since there are different influencing factors such as groundwater conditions, grain size distributions and mineralogy, the rate of increase could not be exactly defined. The variation of limit pressure, $\mathrm{P}_{\mathrm{L}}$, with depth is given in Figure $3 \mathrm{c}$. The average value of $\mathrm{P}_{\mathrm{L}}$ is calculated as $2.1 \mathrm{MPa}$ and the standard deviation is obtained as $0.68 \mathrm{MPa}$. The modulus of the pressuremeter also displayed an increase with increasing depth. The variation of the parameters presented in Figure 3 is belonging to both clayey and sandy soils. Therefore the data were scattered in a larger area and a clear trend could not be determined. Nevertheless, a fitting line as representative was drawn in conjunction with both lower and upper bounds. The equations depicted on each of the graphical demonstrations are representing the fitted relationship between the investigated pairs of parameters. 
Yıldız / Eskişehir Technical Univ. J. of Sci. and Tech. A - Appl. Sci. and Eng. 22 (2) - 2021
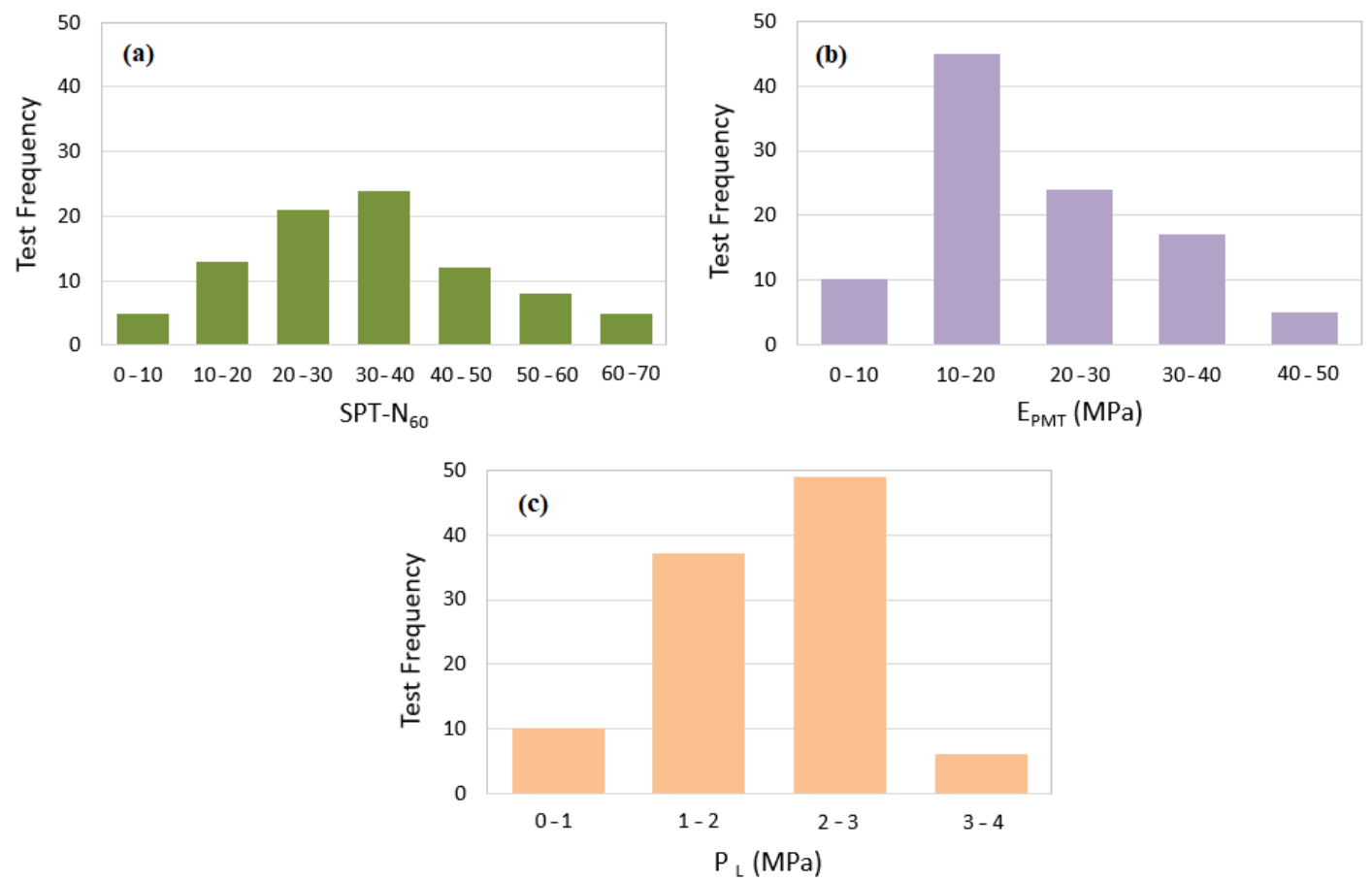

Figure 2. Histograms of the in situ test data; a. SPT-N 60 , b. $\mathrm{E}_{\mathrm{PMT}}$, c. $\mathrm{P}_{\mathrm{L}}$

The variation of the measured data with depth for sandy soils is presented in Figures $4 \mathrm{a}, 4 \mathrm{~b}$ and $4 \mathrm{c}$. The upper and lower bounds are indicated with dashed lines. The average SPT $\mathrm{N}_{60}$, EPMT and $\mathrm{P}_{\mathrm{L}}$ values for sandy soils are 41.6, 25.9 and 2.37, respectively. It was observed that each parameter obtained from field measurements has an increasing trend with increasing depth. The SPT-N 60 values are ranged between 10 to 67 . Based on the upper and lower values of SPT- $\mathrm{N}_{60}$, sandy soils were described as ranging from medium, dense to very dense in accordance with Bowles [27]. The two parameters taken from the pressuremeter test, $\mathrm{E}_{\mathrm{PMT}}$ and $\mathrm{P}_{\mathrm{L}}$ are increased with increasing depth.

The variation of the measured parameters for clayey soils with depth is shown in Figures $4 d, 4 e, 4 f$. The average of SPT- $\mathrm{N}_{60}, \mathrm{E}_{\mathrm{PMT}}$ and $\mathrm{P}_{\mathrm{L}}$ values are calculated as 30, 20 and 1.9, respectively. There is an increase of each measured parameter with increasing depth. Especially for $\mathrm{E}_{\mathrm{PMT}}$, the effect of increasing depth can not be clearly defined due to the scattered data. Researchers explain the much-scattered pressuremeter data of clayey soils by being easily affected by the rapidly changing moisture content, which causes the variation of consistency [17]. Additionally, the scattering data is also attributed to the factors such as groundwater condition, grain size distribution and mineralogy [16]. Therefore, the lower and upper bounds drawn are contributive in terms of showing the measured maximum and minimum ranges within the analyzed dataset. 

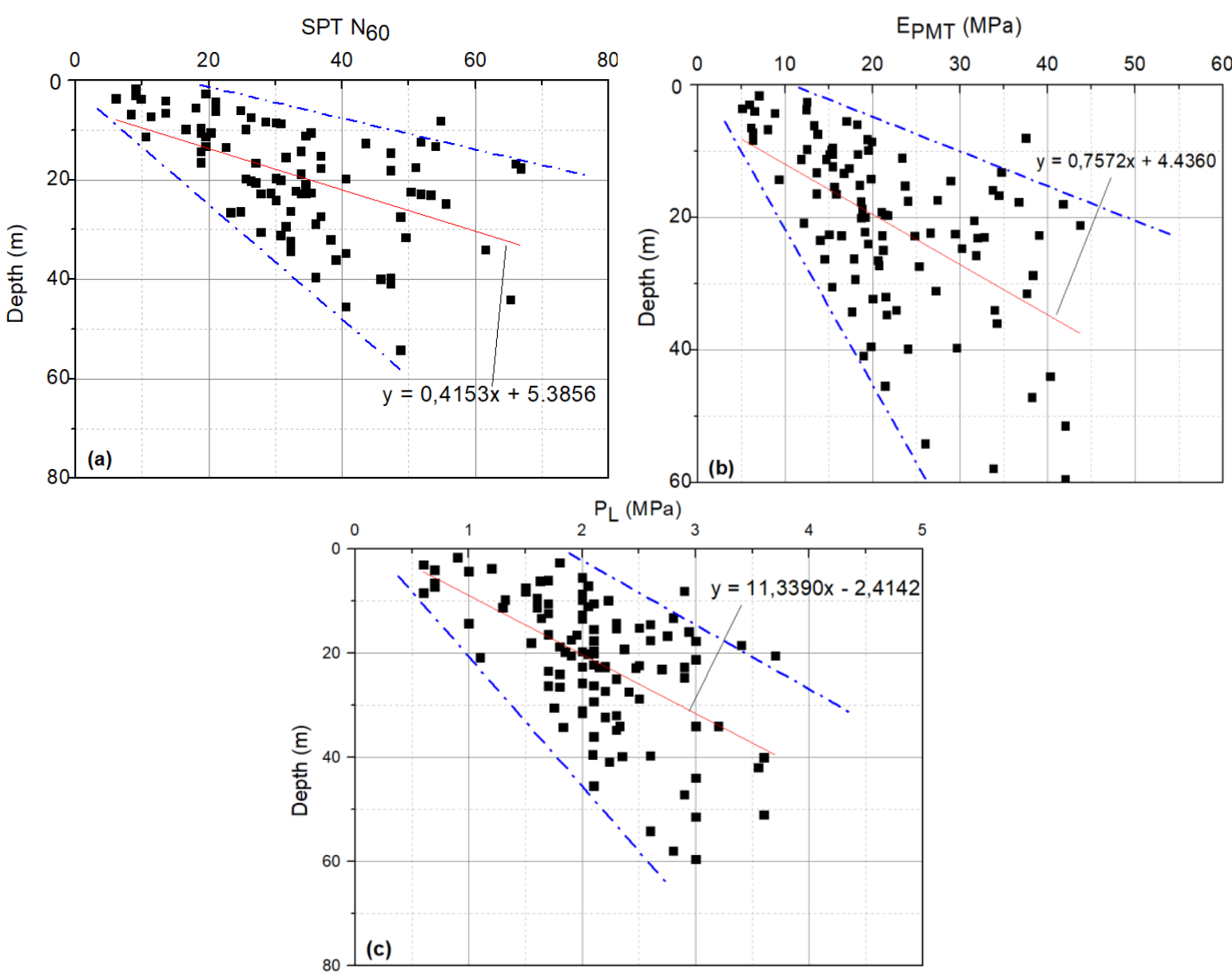

Figure 3. The variation of the measured parameters for all type of soil with depth

The correlation between $\mathrm{E}_{\mathrm{PMT}}$ and SPT-N 60 for sandy and clayey soils is presented in Figure 5. The correlation coefficient between SPT- $\mathrm{N}_{60}$ and $\mathrm{E}_{\mathrm{PMT}}$ for sandy soils is calculated as $\mathrm{R}^{2}=0.81$ which is proof of a high correlation. The relationship between these two parameters is expressed by the following equation;

$$
\mathrm{E}_{\mathrm{PMT}}=0,5187 \mathrm{~N}_{60}+3,3673
$$

As can be seen from Figure 5b, the data scattered in a wider area for clayey soils. The correlation coefficient between $\mathrm{E}_{\mathrm{PMT}}$ and $\mathrm{SPT}-\mathrm{N}_{60}$ is calculated as $\mathrm{R}^{2}=0.52$. The empirical equation between these two parameters is established as below;

$$
\mathrm{E}_{\mathrm{PMT}}=0,4121 \mathrm{~N}_{60}+6,1614
$$

The effecting parameters of clays on pressuremeter moduli such as stress history, fissured fabric, plasticity, mineralogy and moisture content may lead to different orientations of the data and the establishment of the regression line. Therefore, for the considered dataset, the SPT- $\mathrm{N}_{60}$ values of sandy soils were observed to have a higher influence on $\mathrm{E}_{\mathrm{PMT}}$ in comparison to clayey soils. 
Yıldız / Eskişehir Technical Univ. J. of Sci. and Tech. A-Appl. Sci. and Eng. 22 (2) - 2021
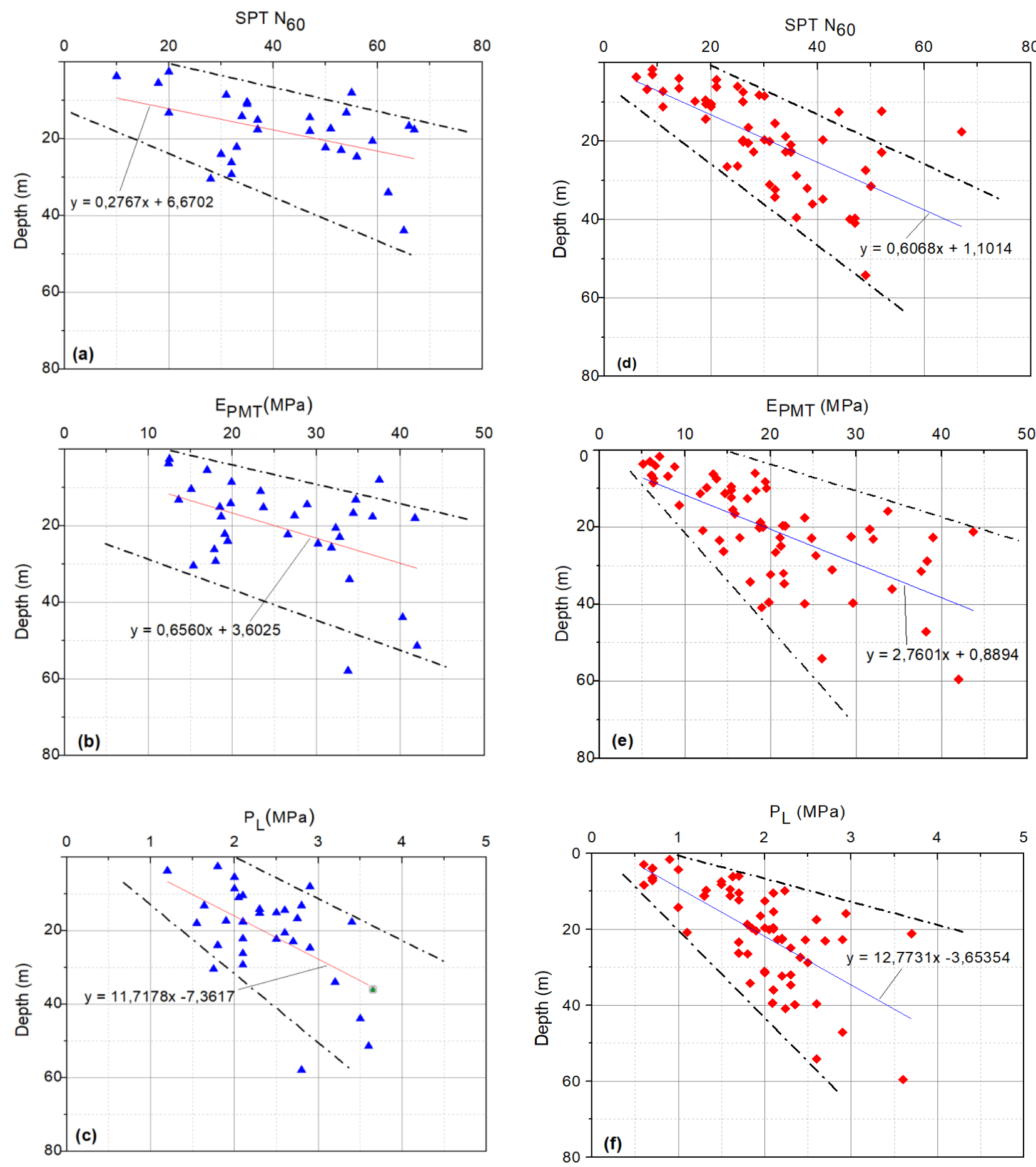

Figure 4. The variation of the measured parameters with depth for a., b., c., sandy soils and d.,e.,f., clayey soils 
Yıldız / Eskişehir Technical Univ. J. of Sci. and Tech. A-Appl. Sci. and Eng. 22 (2) - 2021
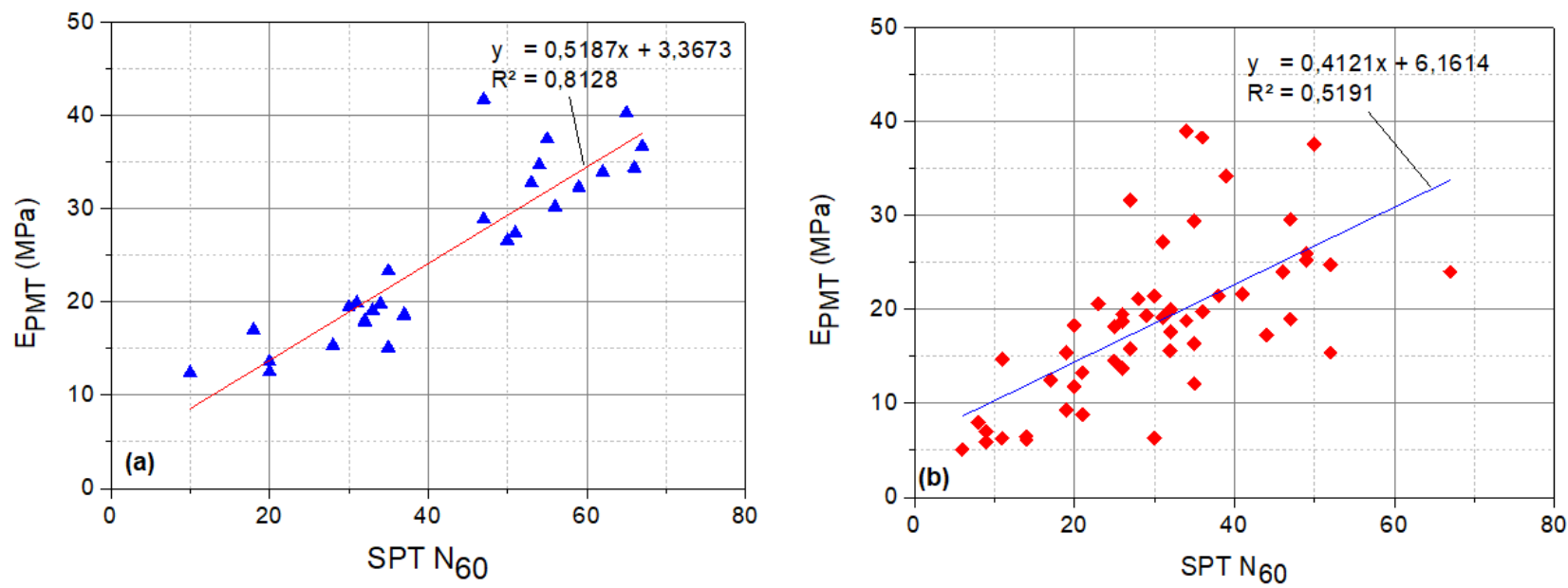

Figure 5. The correlation between $\mathrm{SPT}-\mathrm{N}_{60}$ and $\mathrm{E}_{\mathrm{PMT}}$ for a. sandy soils, b. clayey soils.

The correlation between SPT- $\mathrm{N}_{60}$ and $\mathrm{P}_{\mathrm{L}}$ for sandy and clayey soils is demonstrated in Figure 6. The correlation coefficient, $\mathrm{R}^{2}$, between the investigated parameters of sandy and clayey soils are calculated as 0.72 and 0.60 , respectively. The empirical equations proposed for sandy and clayey soils were expressed as;

$$
\begin{gathered}
P_{L}=0.0265 \mathrm{~N}_{60}+1.1745, \\
P_{L}=0.0329 \mathrm{~N}_{60}+0.7978
\end{gathered}
$$

As for $E_{\text {PMT }}$, the correlation coefficient of sandy soils is observed to have higher values than clayey soils. While the correlation coefficients obtained for sandy soils were very close to the values obtained by Bozbey and Toğrol [16], the correlation coefficients obtained for clayey soils had lower values.
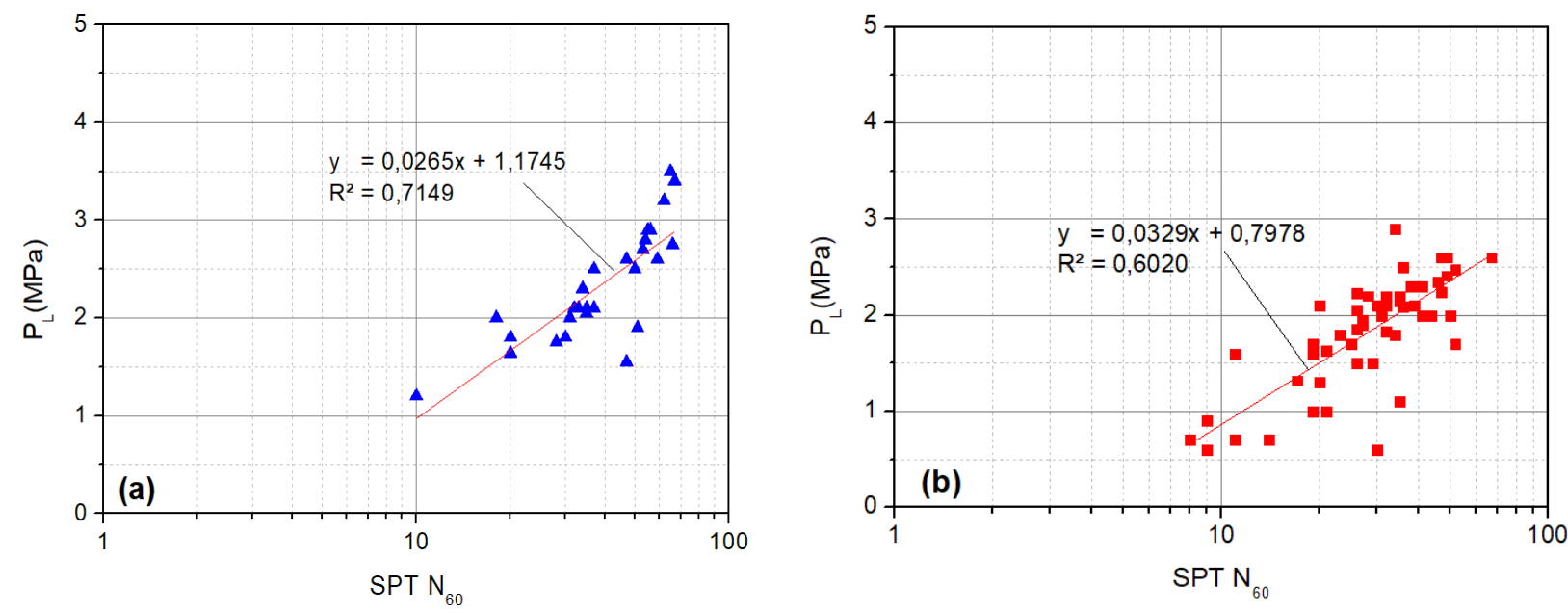

Figure 6. The correlation between SPT- $\mathrm{N}_{60}$ and $\mathrm{P}_{\mathrm{L}}$ for $\mathbf{a}$. sandy soils, b. clayey soils.

Researchers used $\mathrm{E}_{\mathrm{PMT}} / \mathrm{P}_{\mathrm{L}}$ ratios to classify the soils. In some of the studies, this ratio is normalized with atmospheric pressure instead of limit pressure. Clays having the $\mathrm{E}_{\mathrm{PMT}} / \mathrm{P}_{\mathrm{L}}$ ratio ranging between 8 to 10 and 10 to 20 are classified as soft to firm and stiff to very stiff clays, respectively [28]. Baguelin [29] has classified the soils having $\mathrm{E}_{\mathrm{PMT}} / \mathrm{P}_{\mathrm{L}}$ ratios between 7 and 19 as medium-dense to dense sands and 4 to 7 as very loose to loose sands. Accordingly, the investigated sandy soils representing $E_{P M T} / P_{L}$ ratios 
between 7.5 and 15 can be classified as medium-dense to dense sand (Figure $7 \mathrm{a}$ ). The $\mathrm{E}_{\mathrm{PMT}} / \mathrm{P}_{\mathrm{L}}$ ratio of clayey specimens shows a much wider range of scattering. Clayey specimens can be described as soft to firm and stiff to very stiff clays with ratios ranging between 7.5 and 18 (Figure 7b).
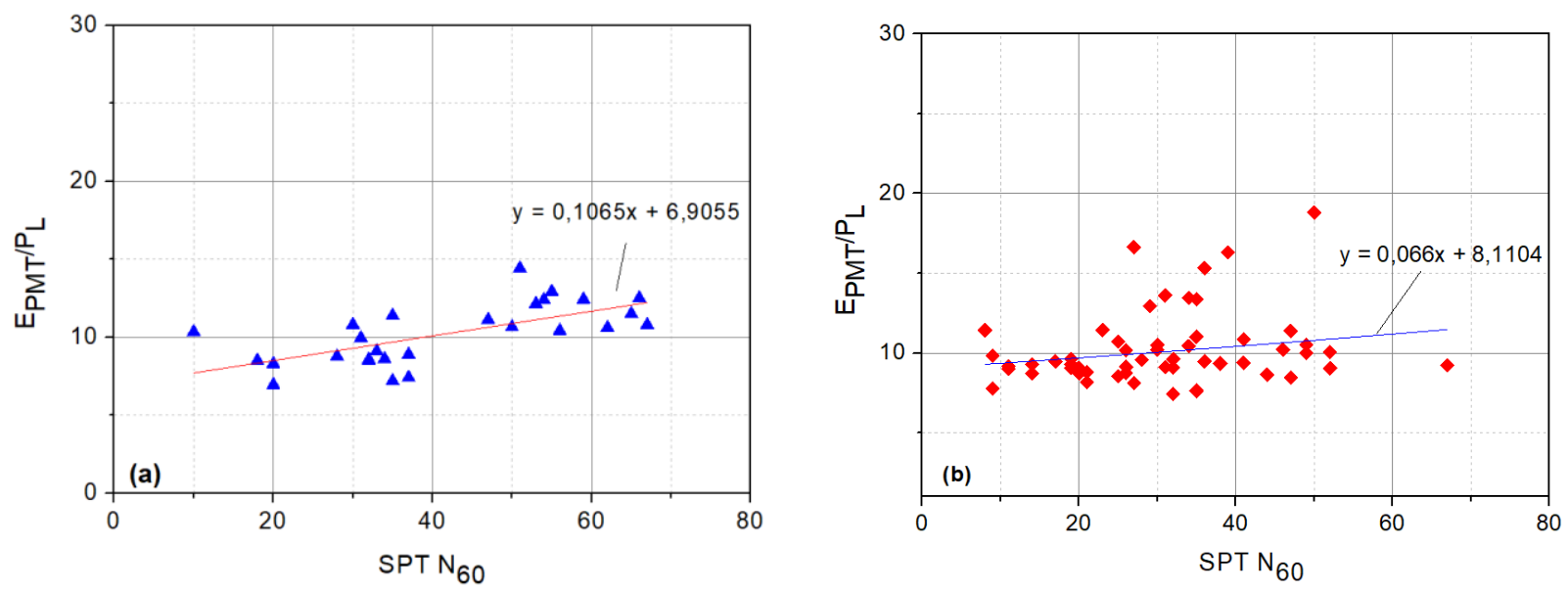

Figure 7. The correlation between $\mathrm{SPT}-\mathrm{N}_{60}$ and $\mathrm{E}_{\mathrm{PMT}} / \mathrm{P}_{\mathrm{L}}$ for $\mathbf{a}$. sandy soils, b. clayey soils.

\section{PREDICTION MODEL}

Neural networks (NNs) are structures developed by imitating the learning ability of humans. These structures produce solutions to the problems they encounter by using the information introduced to them. These networks consist of layers namely; the input layer, the hidden layer, and the output layer. Elements called neurons in layers are connected to each other through weighted connections. The information processing is carried out with the transfer functions in the memory of the network, and the solution of the problem is presented as the output layer. If the solution obtained is not at desired accuracy, the network architecture is changed to repeat the training, thus, the desired success level can be achieved. Today, NNs are used in every field of science that includes estimation, classification, data association, data interpretation and data filtering.

Using the data of both types of soils; clayey and sandy, a multilayer perceptron NN model was developed to estimate $\mathrm{E}_{\mathrm{PMT}}$ and $\mathrm{P}_{\mathrm{L}}$. An input layer with four input parameters namely; depth, effective stress, SPT$\mathrm{N}_{60}$, and soil type were defined. A hidden layer with 10 neurons displayed the best prediction performance by a series of trial-and-error processes with different numbers of neurons. The output layer consists of two neurons namely; $\mathrm{E}_{\mathrm{PMT}}$ and $\mathrm{P}_{\mathrm{L}}$. The architecture of the proposed NN model is given in Figure 8 . The presented data is obtained by field studies and randomly divided into three subsets; 50 of 102 data for the training phase, 26 of 102 data for each validation, and the testing phases. Matlab R2020b software program was used for calculations. The scaled conjugate gradient algorithm requiring less memory, the Levenberg-Marquardt algorithm fastest but requiring more memory and the Bayesian regularization algorithm resulting in good generalization for the difficult, small, or noisy dataset are buried in the software program as default. In this study, the Levenberg-Marquardt algorithm was used due to its fast calculation. The tangent sigmoid activation function is used as a transfer function. The performance of the trained, validated and tested network with the presented data was evaluated according to MSE and $\mathrm{R}^{2}$ values. The best validation performance curve of the NN model can be seen in Figure 9. Both test and validation stage errors have similar characteristics. As can be seen, the minimum MSE value was reached in the 4th iteration, after that no significant overfitting occurred. 


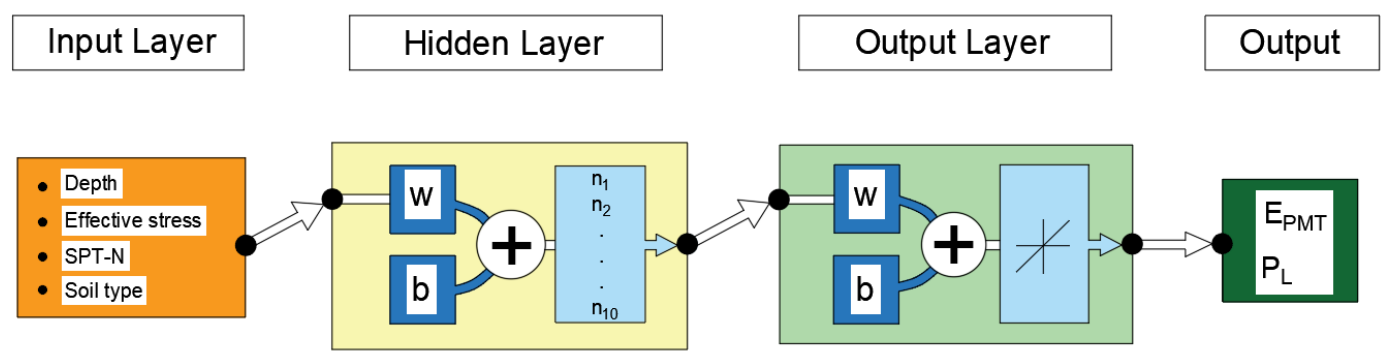

Figure 8. Architecture of the proposed model

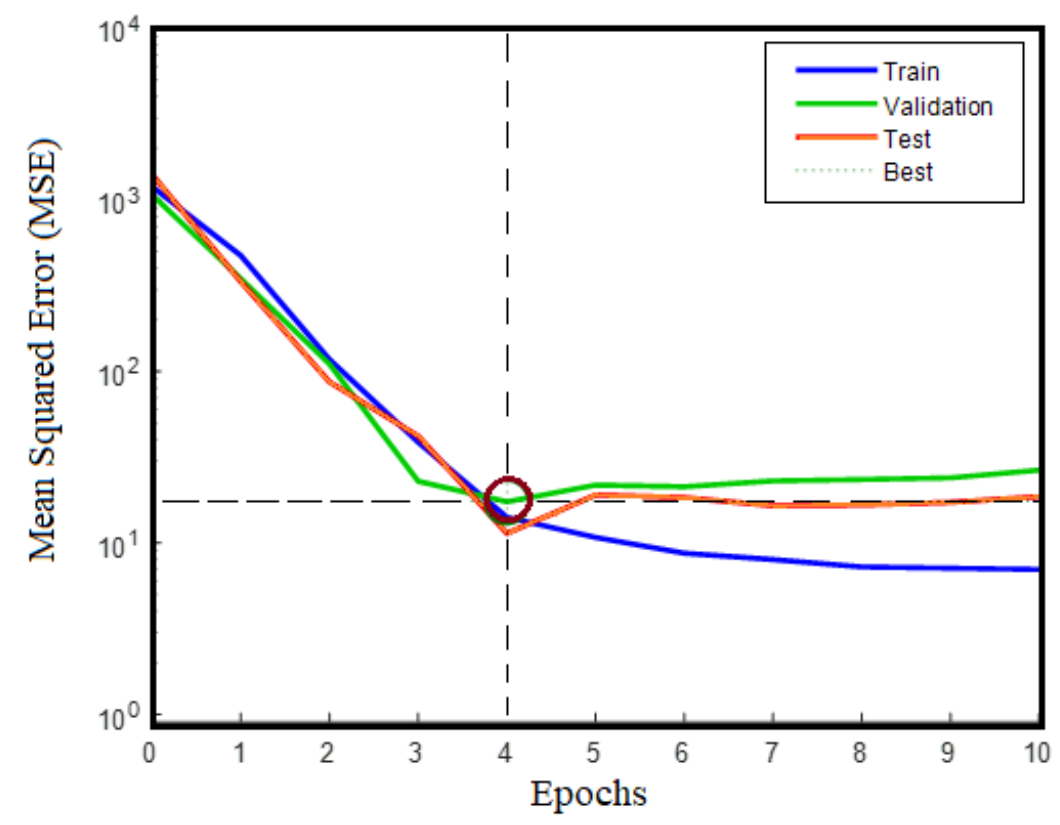

Figure 9. The calculated MSE vs.number of iterations

The accuracy of the predicted values was determined by comparing them with the results of the experiments. Figure 10 shows the regression curves obtained for $\mathrm{E}_{\mathrm{PMT}}$ and $\mathrm{P}_{\mathrm{L}}$ parameters. The field test results are given on the $\mathrm{x}$-axis as target values and the results of numerical analysis are shown on the $\mathrm{y}$ axis as predicted values. The performance evaluation of the model has been achieved using $\mathrm{R}^{2}$ values. The linear output displays the accuracy of the predicted values. The closer $\mathrm{R}^{2}$ coefficient to 1 represents the satisfactory performance of the proposed model. The correlation coefficient $\mathrm{R}^{2}$ between measured and predicted $\mathrm{E}_{\mathrm{PMT}}$ is obtained as 0.91 for sandy soils. The $\mathrm{E}_{\mathrm{PMT}}$ data are scattered in a narrower band for clayey soils. As a result, the correlation coefficient is obtained as 0.92 for clayey soils. A satisfactorily high correlation coefficient value obtained for the prediction of $E_{\text {PMT }}$ for both types of soils which displaying highly accurate prediction performance. The regression curves between measured and predicted $P_{L}$ values are given in Figure 11. As can be seen, the correlation coefficient obtained is sufficiently high as 0.93 for sandy soils. Although it is not as high as sandy soils, the correlation coefficient of clayey soils is also acceptable as 0.80 . In general, the prediction performance of the model is quite successful. This high success is an indicator of the high quality of the soil data employed. 

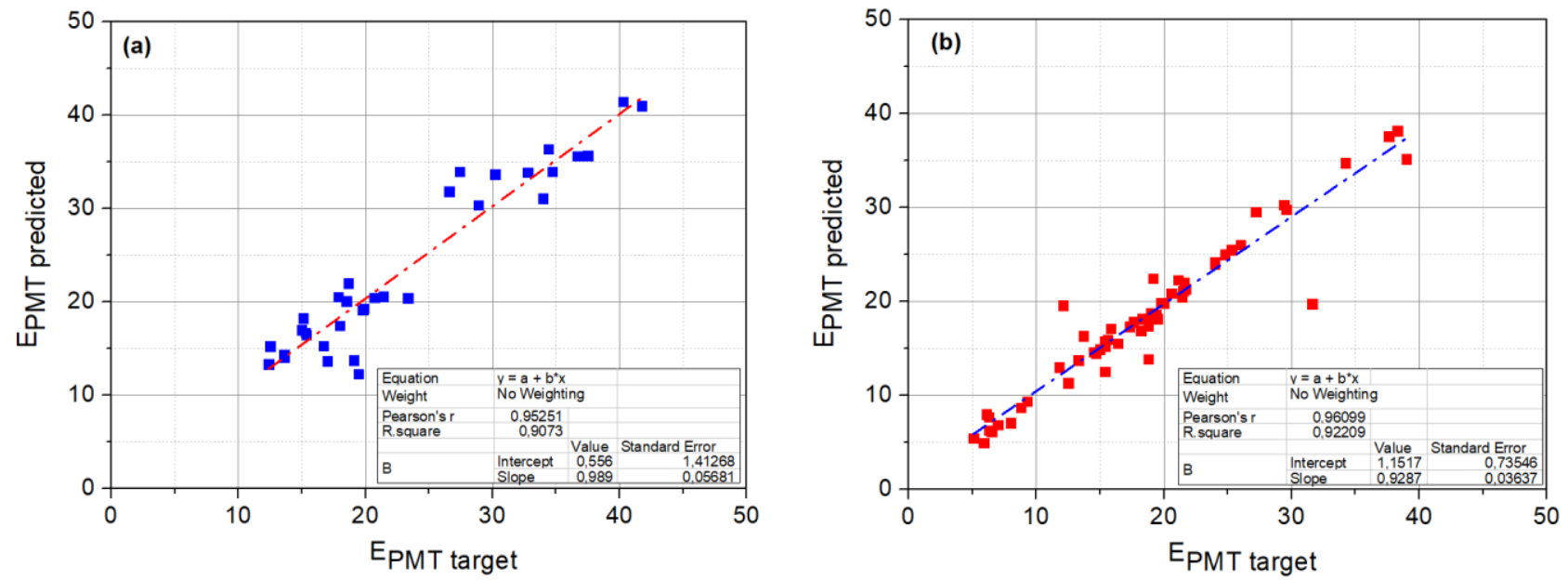

Figure 10. The measured vs. predicted values of $E_{P M T}$ for a. sandy soils, b. clayey soils
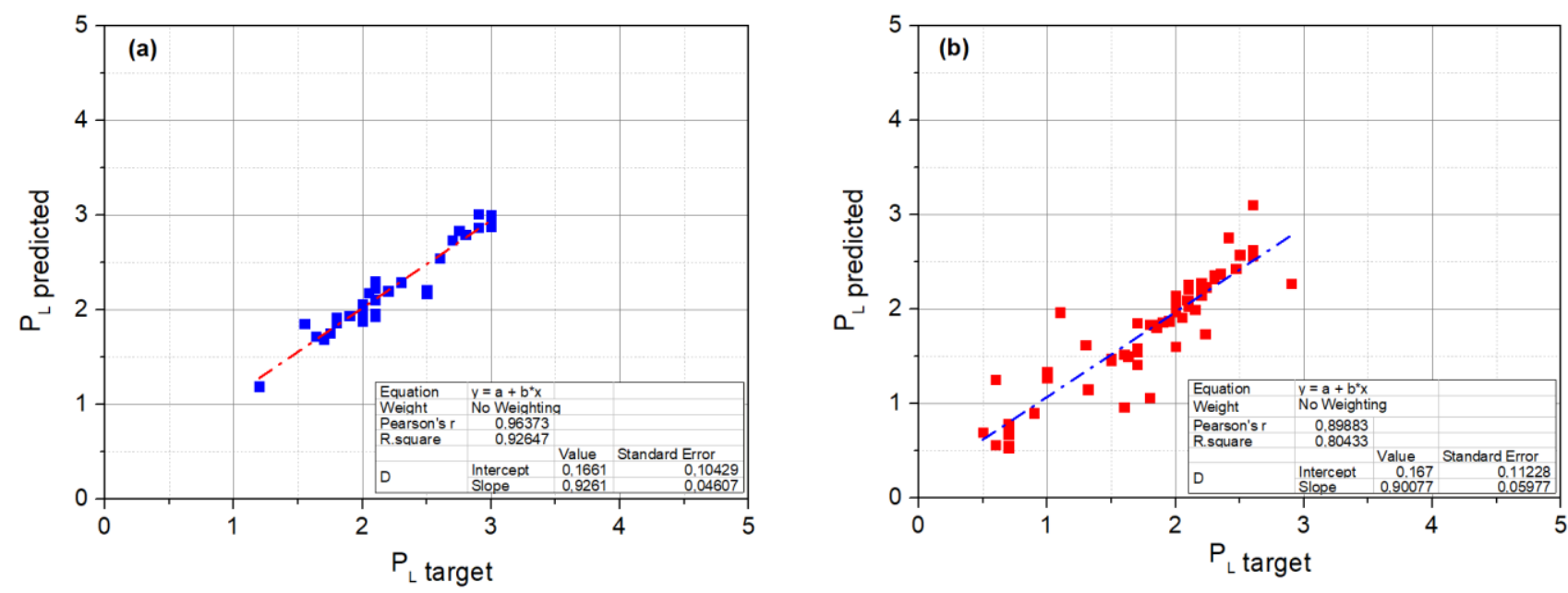

Figure 11. The measured vs. predicted values of $P_{L}$ for a. sandy soils, b. clayey soils

\section{CONCLUSION}

It is almost impossible to carry out studies representing local soil properties with $100 \%$ accuracy in field investigations. The reasons for this can be listed as the difficulties of taking undisturbed specimens, factors depending on the equipment and the operator, reaching the specimen to the laboratory after a long time, etc. These problems, which significantly affect the test results can be overcome by in-situ field tests. The correlations developed between the results of the in-situ tests are therefore important in terms of both providing cross-checking of the results and preliminary information about the field to the designers. This study aimed to correlate SPT and PMT data obtained from soil investigations in Istanbul. In this context, empirical equations were proposed between $\mathrm{E}_{\mathrm{PMT}}, \mathrm{P}_{\mathrm{L}}$ and SPT- $\mathrm{N}_{60}$ for clayey and sandy soils separately. Using the soil data, a NN based forecast model developed and $\mathrm{E}_{\mathrm{PMT}}$ and $\mathrm{P}_{\mathrm{L}}$ parameters were predicted. Based on the studies carried out the following results can be drawn;

- All of the derived equations for sandy soils have high regression coefficients. However, the correlation coefficients of the studied clayey soils are somewhat lower than those of sandy soils. This result is attributed to the affecting parameters such as stress history, fissured fabric, plasticity, mineralogy, and moisture content. 
- The proposed model predicted $E_{P M T}$ and $P_{L}$ parameters of both soil types with high accuracy depending on SPT-N 60 . This shows that as an experience-based method, NNs can be used as an alternative tool to estimate soil parameters.

- The proposed equations and prediction models can be used in the early stage geotechnical investigations. However, it should be emphasized that the equations developed in this study are obtained by using a limited number of data. Therefore, they are useful for similar soil conditions and parameters in the respective ranges. The validity of the empirical equations is often limited only by their own data.

- Since generalized correlations are developed by using data of various soil conditions, local correlations are more convenient to be used for specific soil conditions.

\section{CONFLICT OF INTEREST}

The author stated that there are no conflicts of interest regarding the publication of this article.

\section{REFERENCES}

[1] Sanglerat G. The Penetration and Soil Exploration; Interpretation of Penetration-Diagrams Theory and Practice. Elsevier Publishing Co, Amsterdam, 1997.

[2] Terzaghi K, Peck RB. Soil Mechanics in Engineering Practice. New York, NY, USA: Wiley, 1967.

[3] Kögler F. Baugrundprüfung im Bohrloch. Der Bauingenieur 1933; 14: 266-27.

[4] Menard L. Mesure in-situ des proprietes des sols Annales des ponts et chaussees 1957;14:357377.

[5] Leischner W. Die bautechnische Baugrundbeurteilung mittels horizontaler Belastungsversuche im Bohrloch nach dem Koglerverfahren. Der Bauingenier 1966; 12.

[6] Shields DH, Bauer GH. Determination of the modulus of deformation of sensitive clay using laboratory and in situ tests. In: Proceedings of the ASCE Special Conference on in situ measurement of soil properties, Raleigh, 1975; 1: 395-421.

[7] Lee KM, RK Rowe. Deformation caused by surface loading and tunneling: the role of elastic anisotropy. Geotechnique 1989; 39(1):125-140.

[8] Ohya S, Imai T, Matsubara M. Relation between N value by SPT and LLT pressuremeter results in Proceeding 2nd European Symposium on Penetration Testing, Amsterdam, 1982;1: 125-130.

[9] Briaud JL. The Pressuremeter. A.A. Balkema, Rotterdam, 1992.

[10] Gonin H, Vandangeon P, Lafeullade MP. Correlation study between standard penetration and pressuremeter tests. Rev Fr Ge'otech 1992; 58:67-78.

[11] Yagiz S, Akyol E, Sen G. Relationship between the standard penetration test and the pressuremeter test on sandy silty clays: A case study from Denizli. Bulletin of Engineering Geology and the Environment, 2008; 67(3): 405-410. 
[12] Alzubaidi R. Variations in pressuremeter modulus (EM). International Journal of GEOMATE 2016; 10(1): 1675-1679.

[13] Kenmogne E, Martin JR, Geofor, SA. Correlation studies between SPT and Pressuremeter tests, in: Proceedings of the 15th African Regional Conference on Soil Mechanics and Geotechnical Engineering, 2011.

[14] Cheshomi A, Ghodrati M. Estimating Menard pressuremeter modulus and limit pressure from SPT in silty sand and silty clay soils. A case study in Mashhad, Iran Int. J. Geomech. Geoeng. 2014; 10(3): 194-202.

[15] Anwar M.B. Correlation between PMT and SPT results for calcareous soil. HBRC Journal, 2018; 14(1): 50-55.

[16] Bozbey I, Togrol E. Correlation of standard penetration test and pressuremeter data: A case study from Istanbul, Turkey. Bulletin of Engineering Geology and the Environment 2010; 69(4): 505515 .

[17] Kayabasi A. Prediction of pressuremeter modulus and limit pressure of clayey soils by simple and non-linear multiple regression techniques: A case study from Mersin, Turkey. Environmental Earth Sciences 2012; 66(8): 2171-2183.

[18] Aladag CH, Kayabasi A, Gokceoglu C. Estimation of pressuremeter modulus and limit pressure of clayey soils by various artificial neural network models. Neural Computing and Applications $2013 ; 23(2): 333-339$.

[19] Agan C. Silt Biriminde (Kastamonu, Türkiye) Yapılan Menard Presiyometre, Standart Penetrasyon ve Laboratuvar Deney Sonuçları Arasındaki İlişkilerin Araştırılması. Teknik dergi 2013; 6679-6698.

[20] Balachandran K, Liu J, Cao L, Peaker S. Statistical Correlations between Pressuremeter Tests and SPT for Glacial Tills. In: Fourth Geo-China International Conference 25-27 July 2016; Shandong, CHINA: pp.133-140.

[21] Narimani S, Chakeri H, Davarpanah SM. Simple and Non-Linear Regression Techniques Used in Sandy-Clayey Soils to Predict the Pressuremeter Modulus and Limit Pressure: A Case Study of Tabriz Subway. Periodica Polytechnica Civil Engineering 2018; 62(3): 825-839.

[22] Kavur B, Dodigovic F, Jug J, Strelec S. The Interpretation of CPTu, PMT, SPT and Cross-Hole Tests in Stiff Clay. IOP Conference Series: Earth and Environmental Science 2019; 221(1).

[23] Önal M, Ceylan Ç. Correlations Between SPT, PMT and MASW on Quaternary Alluvial - Fluvial Sediments in Battalgazi, Malatya, Turkey. NATURENGS MTU Journal of Engineering and Natural Sciences, Malatya Turgut Ozal University, 2020; 1(2): 39-53.

[24] Zaki MFM, Ismail MAM, Govindasamy D, Zainalabidin MH. Correlation between PMT and SPT results for Kenny hill formation. Bulletin of the Geological Society of Malaysia, 2019; 68(December): 141-146.

[25] Phoon K. Kulhawy F. Evaluation of geotechnical variability. Can. Geotech. J 1999; 36 (4): 625639. 
[26] Yıldırım M,Tonaroğlu M, Selçuk ME. Akgöner C. Revised stratigraphy of the tertiary deposits of Istanbul and their engineering properties. Bulletin of Engineering Geology and the Environment 2013; 72(3-4).

[27] Bowles JE. Foundation Analysis and Design. 2nd ed. McGraw-Hill, Inc., New York, 1977.

[28] Clarke BG. Pressuremeters in Geotechnical Design. Chapman \& Hall, Glasgow, 1st ed. 1995.

[29] Baguelin F. Rules of foundation design using self boring pressuremeter results. In: Proceedings of international symposium on pressuremeter marine applications, 1982; pp. 347-360. 